\title{
An infrared spectroscopic and temperature-programmed desorption study of methyl iodide hydrogenation on $\operatorname{Pd}\left(\begin{array}{lll}1 & 1 & 1\end{array}\right)$
}

\author{
D. Stacchiola, Y. Wang, W.T. Tysoe * \\ Department of Chemistry and Laboratory for Surface Studies, University of Wisconsin-Milwaukee, P.O. Box 413, \\ Milwaukee, WI 53211, USA
}

Received 26 August 2002; accepted for publication 30 October 2002

\begin{abstract}
The adsorption and hydrogenation of methyl iodide is studied on clean and hydrogen-covered $\operatorname{Pd}\left(\begin{array}{lll}1 & 1 & 1\end{array}\right)$ using reflection-adsorption infrared spectroscopy (RAIRS) and temperature-programmed desorption. Molecular methyl iodide desorbs from clean Pd(1 1 1) at $229 \mathrm{~K}$ and hydrogen desorbs at $\sim 360 \mathrm{~K}$. Methyl groups hydrogenate in two states at 191 and $304 \mathrm{~K}$ for large methyl iodide exposures where RAIRS data suggest that the low-temperature state is due to reaction with tilted methyl species while the high-temperature state is formed by hydrogenation of perpendicular ones. A single state is found at low methyl iodide coverages at $\sim 219 \mathrm{~K}$ due to the hydrogenation of tilted methyl species where the kinetics is limited by the rate of $\alpha$-hydrogen elimination. Saturating the surface with hydrogen completely suppresses the high-temperature methane desorption state and the methane desorbs at between 189 and $207 \mathrm{~K}$ depending on coverage.
\end{abstract}

(C) 2002 Elsevier Science B.V. All rights reserved.

Keywords: Palladium; Halides; Infrared absorption spectroscopy; Thermal desorption spectroscopy; Surface chemical reaction

\section{Introduction}

Iodine-containing molecules have been extensively used to deposit hydrocarbon fragments onto transition-metal surfaces to provide a fundamental understanding of catalytic hydrocarbon conversion reactions, such as Fisher-Tropsch synthesis, olefin metathesis and alkene hydrogenation [1-3]. It was previously shown that ethyl species formed

\footnotetext{
${ }^{*}$ Corresponding author. Tel.: +1-414-229-5222; fax: +1-414229-5036.

E-mail address: wtt@uwm.edu (W.T. Tysoe).
}

on $\operatorname{Pd}\left(\begin{array}{lll}1 & 1 & 1\end{array}\right)$ from ethyl iodide reacted with hydrogen to form ethane much more rapidly than did adsorbed ethylene, suggesting that the rate-limiting step in the reaction of adsorbed ethylene to ethane was the addition of the first hydrogen to ethylene to form an ethyl species [4]. In order to further understand these elementary hydrogenation steps on $\operatorname{Pd}\left(\begin{array}{lll}1 & 1 & 1\end{array}\right)$, the surface chemistry and hydrogenation reactions of methyl species adsorbed on $\mathrm{Pd}\left(\begin{array}{lll}1 & 1 & 1\end{array}\right)$ from its corresponding iodide is investigated in the following. Methyl iodide adsorption and the formation of the corresponding methyl species have been previously studied on several transition metals [1,2]. Silver [5] and gold [6] appear to exhibit unique behaviors since alkyl 
species do not self-hydrogenate to methane on these surfaces, but rather tend to dimerize [7,8]. Methane formation is found due to the reductive elimination of methyl species on other transition metals surfaces at $215 \mathrm{~K}$ on $\mathrm{Pd}(100)$ [9], $230 \mathrm{~K}$ on $\mathrm{Ni}\left(\begin{array}{ll}1 & 0\end{array}\right)$ [10] and $260 \mathrm{~K}$ on $\mathrm{Pt}\left(\begin{array}{lll}1 & 1 & 1\end{array}\right)$ [11]. Previous temperature-programmed desorption (TPD) studies of $\mathrm{CH}_{3} \mathrm{I}$ and $\mathrm{CD}_{3} \mathrm{I}$ on $\operatorname{Pd}\left(\begin{array}{lll}1 & 1\end{array}\right)$ found only methane desorption at $\sim 210 \mathrm{~K}$ due to reaction of methyl species with hydrogen contamination present in the bulk of the sample [12]. Hydrogen background contamination of palladium has been shown to be a problem even under ultrahigh vacuum conditions. Recent experiments, in which great care was taken to completely remove all hydrogen from the sample, have revealed differences with earlier work, even on extensively studied systems such as ethylene on $\operatorname{Pd}\left(\begin{array}{lll}1 & 1 & 1\end{array}\right)$ [13].

The X-ray photoelectron spectra (XPS) of methyl iodide on $\operatorname{Pd}\left(\begin{array}{lll}1 & 1 & 1\end{array}\right)$ have been collected previously $[12,14]$ and reveal that substantial C-I bond cleavage is underway by $110 \mathrm{~K}$ and is essentially complete by $150 \mathrm{~K}$. Similar conclusions were arrived at on $\operatorname{Pd}\left(\begin{array}{lll}1 & 0 & 0\end{array}\right)$ [9], where XPS similarly indicated that $\mathrm{C}-\mathrm{I}$ bond cleavage occurs between 150 and $170 \mathrm{~K}$, so at slightly higher temperatures than on $\operatorname{Pd}\left(\begin{array}{lll}1 & 1 & 1\end{array}\right)$.

Studies have been carried out on the reaction of methylene species, generated from $\mathrm{CH}_{2} \mathrm{I}_{2}$, with adsorbed oxygen [15-18], and methyl species [19]. In the case of palladium, XPS shows the thermal formation of methylene species from methylene

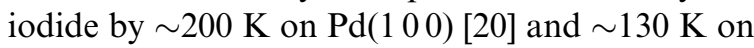
$\operatorname{Pd}\left(\begin{array}{llll}1 & 1 & 0)\end{array}\right]$ [21].

It is shown in the following that adsorbed methyl species on $\operatorname{Pd}\left(\begin{array}{lll}1 & 1 & 1\end{array}\right)$ hydrogenate in two states at 191 and $304 \mathrm{~K}$ where the low-temperature state is due to reaction with tilted methyl species while the high-temperature state is due to reaction with perpendicular ones. Addition of hydrogen to $\operatorname{Pd}\left(\begin{array}{lll}1 & 1 & 1\end{array}\right)$ forms methane at between 189 and $207 \mathrm{~K}$ depending on coverage.

\section{Experimental}

Experiments were carried out in two stainlesssteel, ultrahigh vacuum chambers operating at base pressures of $\sim 8 \times 10^{-11}$ Torr following bakeout, and which have been described in detail elsewhere [22,23]. Infrared data were collected from a $\operatorname{Pd}\left(\begin{array}{llll}1 & 1 & 1\end{array}\right)$ single crystal sample mounted in a modified $23 / 4$ " six-way cross equipped with infrared-transparent, $\mathrm{KBr}$ windows. The sample could be resistively heated to $1000 \mathrm{~K}$, or cooled to $80 \mathrm{~K}$ using liquid nitrogen. Light from a Bruker Equinox infrared spectrometer passed through a polarizer and was focused onto the sample at an incidence angle of $\sim 80^{\circ}$, and the reflected light steered onto the detector of a liquid-nitrogencooled, mercury cadmium telluride detector. The complete light path was enclosed and purged with dry, $\mathrm{CO}_{2}$-free air. The spectrometer operated at $4-\mathrm{cm}^{-1}$ resolution and data were typically collected for 1000 scans.

TPD spectra were collected in a separate ultrahigh vacuum chamber [23] where the sample could be similarly heated and cooled and could be placed in front of a Dycor quadrupole mass analyzer to collect TPD data.

In both cases, the sample was cleaned using a standard procedure and the absence of carbon, the main contaminant after annealing the sample, was confirmed by the absence of CO detected in TPD after dosing the surface with oxygen.

The methyl iodide (Aldrich Chemicals, 99\%), methylene iodide (Aldrich Chemicals, 99.9\%), ethyl iodide (Aldrich Chemicals, 99\%) and perdeuterated $\mathrm{CD}_{3} \mathrm{I}$ (Aldrich Chemicals, $99 \% \mathrm{D}$ ) were transferred to glass vials, attached to the gas-handling line of the vacuum system, and further purified by repeated freeze-pump-thaw cycles and their purities monitored mass spectroscopically.

\section{Results}

\subsection{Methyl iodide adsorption on Pd(111)}

Fig. 1 shows a series of TPD spectra, collected using a heating rate of $7 \mathrm{~K} / \mathrm{s}$, of $6 \mathrm{~L}\left(1 \mathrm{~L}=1 \times 10^{-6}\right.$ Torrs) of $\mathrm{CD}_{3} \mathrm{I}$ adsorbed on $\operatorname{Pd}\left(\begin{array}{lll}1 & 1\end{array}\right)$ at $80 \mathrm{~K}$. Exposures are not corrected for ionization gauge sensitivities and this exposure produces slightly more than the saturation coverage. The 145-amu spectrum is due to the desorption of molecular 


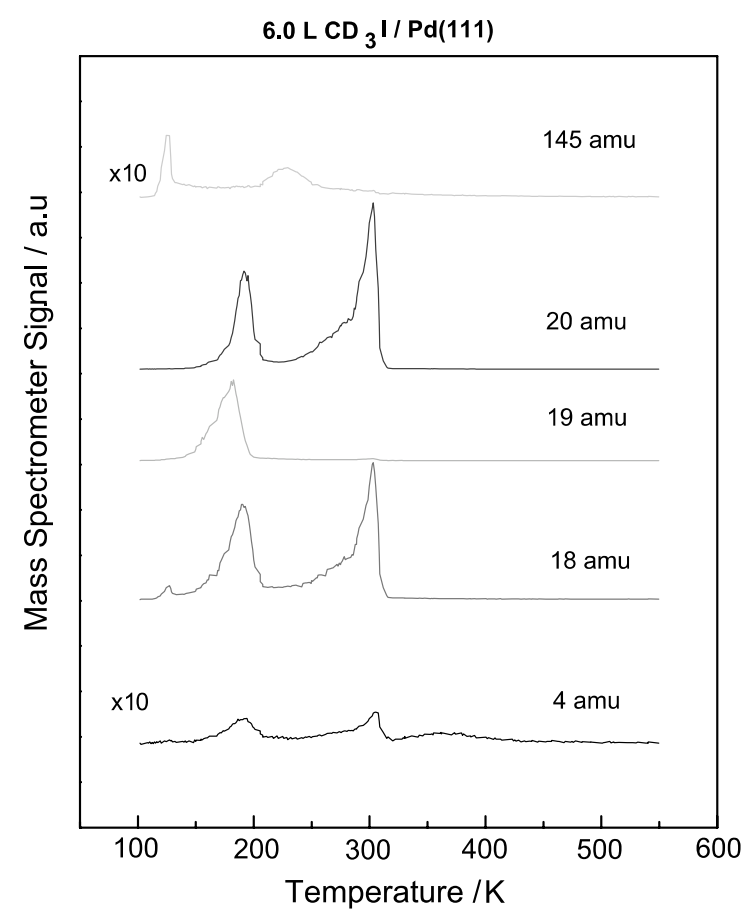

Fig. 1. Survey TPD spectra of $\mathrm{CD}_{3} \mathrm{I}(6 \mathrm{~L})$ adsorbed on $\mathrm{Pd}\left(\begin{array}{lll}1 & 1 & 1\end{array}\right)$ at $80 \mathrm{~K}$ collected using a heating rate of $7 \mathrm{~K} / \mathrm{s}$ monitoring $4\left(\mathrm{D}_{2}\right), 18\left(\mathrm{CD}_{3}\right), 19\left(\mathrm{CD}_{3} \mathrm{H}\right), 20\left(\mathrm{CD}_{4}\right)$ and $145\left(\mathrm{CD}_{3} \mathrm{I}\right)$ $\mathrm{amu}$. The monitored masses are marked adjacent to the corresponding spectrum.

methyl iodide and exhibits a sharp peak at $127 \mathrm{~K}$ which also has a fragment at $18 \mathrm{amu}$. This feature continues to grow with increasing exposure and is assigned to the desorption of methyl iodide multilayers. An additional molecular desorption feature is detected at $229 \mathrm{~K}$ where the corresponding 18 -amu fragment is obscured by the large features at 191 and $304 \mathrm{~K}$ in the 18 -amu spectrum. This desorption temperature is between that found from $\operatorname{Pt}\left(\begin{array}{lll}1 & 1\end{array}\right)$ of $\sim 235 \mathrm{~K}$ [11] and that from $\operatorname{Ag}\left(\begin{array}{lll}1 & 1 & 1\end{array}\right)$ of $\sim 211 \mathrm{~K}$ [5]. Intense features are detected at 191 and $304 \mathrm{~K}$ in the 20- and 18-amu spectra and are assigned to the desorption of methane $\left(\mathrm{CD}_{4}\right)$. Features are evident at these temperatures at $4 \mathrm{amu}$ indicating that these are due to fragmentation of the desorbing methane in the mass spectrometer ionizer. A small feature is detected in the 4-amu spectrum at $\sim 360 \mathrm{~K}$ due to the desorption of molecular $\mathrm{D}_{2}$ and the weakness of this signal indicates that the majority of the surface hydrogen reacts rapidly with adsorbed methyl species to form methane. A feature is detected for the 19-amu fragment at $179 \mathrm{~K}$ and is not due to fragmentation of desorbing $\mathrm{CD}_{4}$ in the mass spectrometer ionizer and is possibly due to the formation of some $\mathrm{CD}_{3} \mathrm{H}$ by reaction between adsorbed $\mathrm{CD}_{3}$ species and residual hydrogen in the sample.

Fig. 2 shows the evolution of the 20-amu (methane) desorption state as a function of $\mathrm{CD}_{3} \mathrm{I}$ exposure, where the exposures are marked adjacent to the corresponding spectrum. This displays a relatively complex behavior having a single methane desorption state at $219 \mathrm{~K}$ for exposures up to $2.0 \mathrm{~L}$, which splits into two states as the exposure exceeds $3.0 \mathrm{~L}$, eventually forming two desorption states at 191 and $304 \mathrm{~K}$ after a 6-L exposure, as shown in Fig. 1.

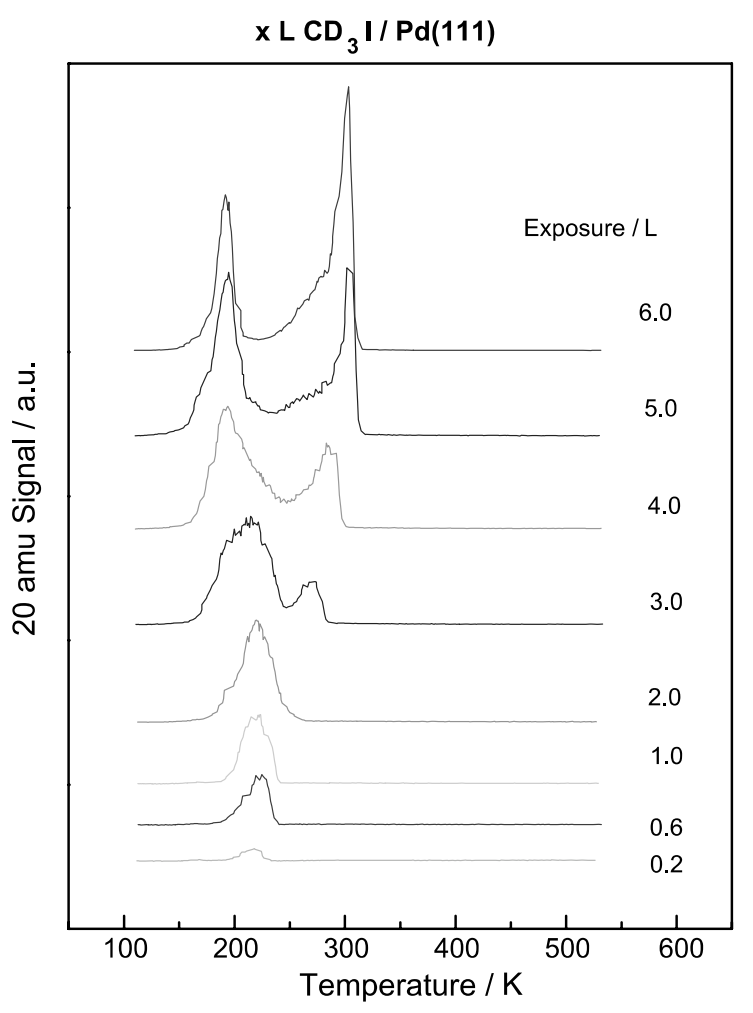

Fig. 2. TPD spectra of $\mathrm{CD}_{3} \mathrm{I}$ adsorbed on $\operatorname{Pd}(111)$ at $80 \mathrm{~K}$ collected using a heating rate of $7 \mathrm{~K} / \mathrm{s}$ monitoring $20 \mathrm{amu}\left(\mathrm{CD}_{3}\right)$ as a function of $\mathrm{CD}_{3} \mathrm{I}$ exposures, where the exposures (in Langmuirs) are marked adjacent to the corresponding spectrum. 
The corresponding 4-amu $\left(\mathrm{D}_{2}\right)$ spectra are displayed in Fig. 3. These show the 219-, 191- and $304-K$ peaks due to fragments of the $\mathrm{CD}_{4}$ desorption state evident in Fig. 2. An additional feature is seen at $\sim 359 \mathrm{~K}$ due to the desorption of residual deuterium from the $\operatorname{Pd}\left(\begin{array}{lll}1 & 1 & 1\end{array}\right)$ surface and the intensity of this feature remains relatively constant up to an exposure of $1 \mathrm{~L}$. It decrease in intensity at exposures above $2 \mathrm{~L}$, coincident with the onset of high-temperature $\mathrm{CD}_{4}$ formation.

The effect of pre-dosing the surface with deuterium is shown in Figs. 4 and 5. Survey spectra are displayed in Fig. 4, collected after pre-dosing the $\operatorname{Pd}\left(\begin{array}{lll}1 & 1 & 1\end{array}\right)$ surface with $10 \mathrm{~L}$ of $\mathrm{D}_{2}$ and then exposing to $6 \mathrm{~L}$ of $\mathrm{CD}_{3} \mathrm{I}$. This exhibits a sharp multilayer desorption feature at $152 \mathrm{~K}$ (with fragments at 145, 18 and $4 \mathrm{amu}$ ). This temperature is slightly higher than the multilayer desorption state from clean $\operatorname{Pd}(111)$ (127 K, Fig. 1). Methane now

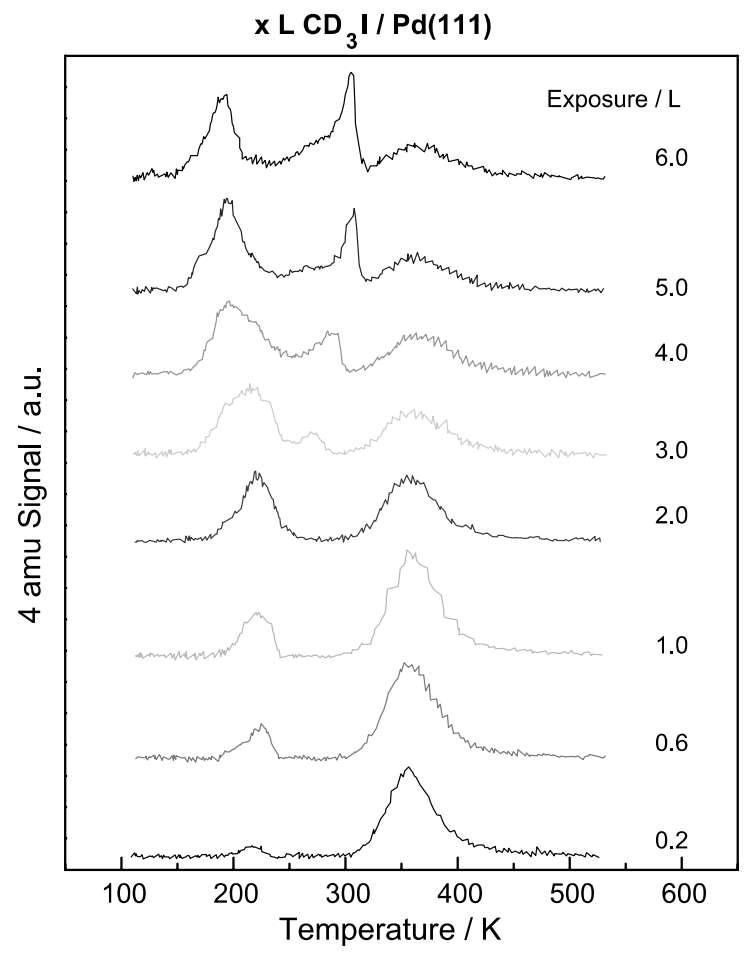

Fig. 3. TPD spectra of $\mathrm{CD}_{3} \mathrm{I}$ adsorbed on $\mathrm{Pd}\left(\begin{array}{lll}1 & 1 & 1)\end{array}\right)$ at $80 \mathrm{~K}$ collected using a heating rate of $7 \mathrm{~K} / \mathrm{s}$ monitoring $4 \mathrm{amu}\left(\mathrm{D}_{2}\right)$ as a function of $\mathrm{CD}_{3} \mathrm{I}$ exposures, where the exposures (in Langmuirs) are marked adjacent to the corresponding spectrum.

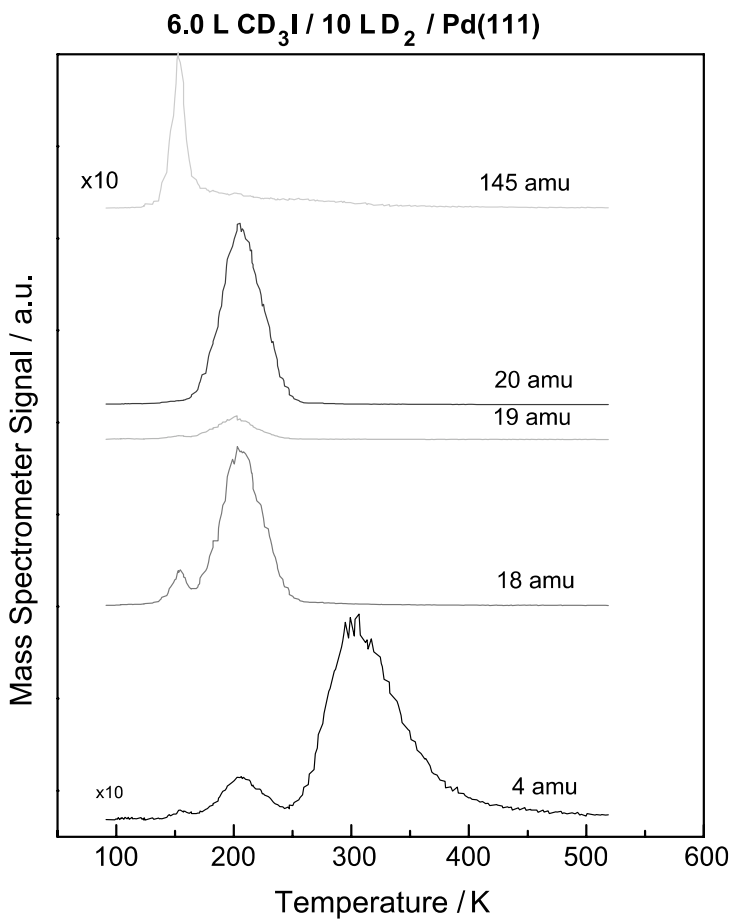

Fig. 4. Survey TPD spectra of $\mathrm{CD}_{3} \mathrm{I}(6 \mathrm{~L})$ adsorbed on deuterium-covered $\mathrm{Pd}\left(\begin{array}{lll}1 & 1 & 1\end{array}\right)$ (following a $10-\mathrm{L} \mathrm{D}_{2}$ exposure) at $80 \mathrm{~K}$ collected using a heating rate of $7 \mathrm{~K} / \mathrm{s}$ monitoring $4\left(\mathrm{D}_{2}\right), 18$ $\left(\mathrm{CD}_{3}\right), 19\left(\mathrm{CD}_{3} \mathrm{H}\right), 20\left(\mathrm{CD}_{4}\right)$ and $145\left(\mathrm{CD}_{3} \mathrm{I}\right) \mathrm{amu}$. The monitored masses are marked adjacent to the corresponding spectrum.

desorbs in a single state centered at $209 \mathrm{~K}$ with mass spectrometer ionizer intensity at 20,18 and 4 amu with a small amount of intensity at 19 amu. This is in good agreement with the desorption temperature of $\mathrm{CD}_{3} \mathrm{H}$ from hydrogen-contaminated $\operatorname{Pd}\left(\begin{array}{lll}1 & 1 & 1\end{array}\right)$ [12]. The 19-amu signal is also centered at $209 \mathrm{~K}$ indicating that this feature is not due to the interaction of adsorbed $\mathrm{CD}_{3}$ species with residual hydrogen in the sample. Remaining deuterium desorbs from the surface at $\sim 300 \mathrm{~K}$. The evolution of the 20- and 18-amu $\left(\mathrm{CD}_{4}\right)$ TPD spectra with exposure is displayed in Fig. 5. These spectra exactly mirror each other confirming that they are due to $\mathrm{CD}_{4}$ desorption from the surface. At low $d_{3}$-methyl iodide exposures $(1$ and $3 \mathrm{~L}$ ), methane desorbs in a single feature centered at $\sim 189 \mathrm{~K}$. As the $d_{3}$-methyl iodide exposure increases, the methane desorption feature shifts to higher temperatures, but maintains a relatively 


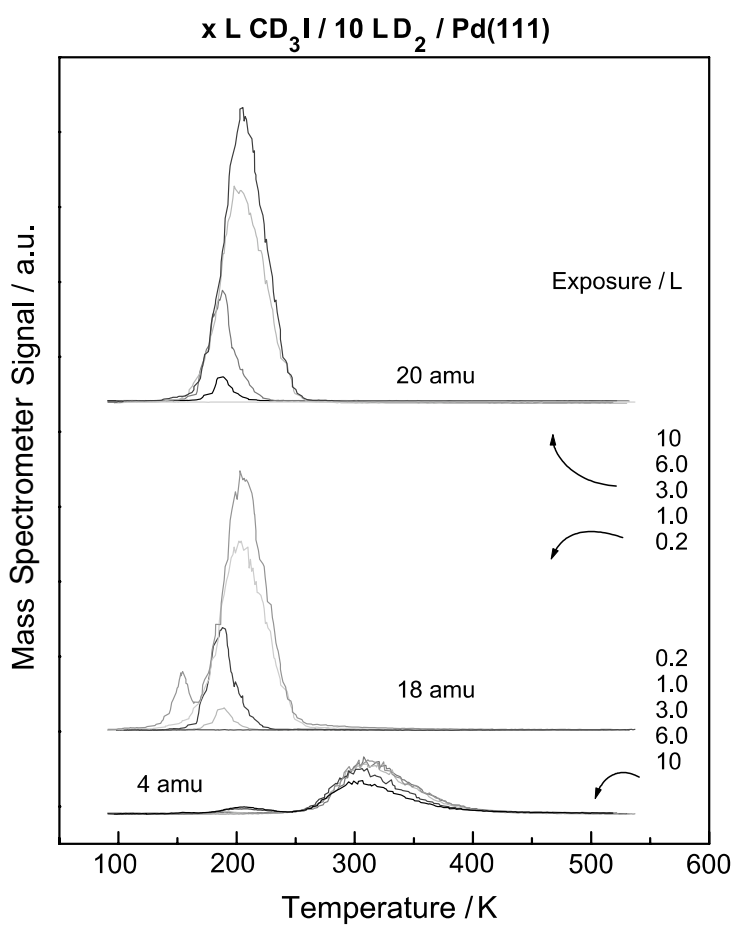

Fig. 5. TPD spectra of $\mathrm{CD}_{3} \mathrm{I}$ adsorbed on deuterium-covered $\operatorname{Pd}\left(\begin{array}{lll}1 & 1 & 1\end{array}\right)$ (following a 10-L deuterium exposure) collected using a heating rate of $7 \mathrm{~K} / \mathrm{s}$ as a function of $\mathrm{CD}_{3} \mathrm{I}$ exposure monitoring $4\left(\mathrm{D}_{2}\right), 18\left(\mathrm{CD}_{3}\right)$ and $20\left(\mathrm{CD}_{4}\right)$ amu. Both the masses and $\mathrm{CD}_{3} \mathrm{I}$ exposures are marked adjacent to the corresponding spectra.

common leading edge, so that after a $\mathrm{CD}_{3} \mathrm{I}$ exposure of $10 \mathrm{~L}$ the methane desorption peak temperature has increased to $207 \mathrm{~K}$.

The corresponding reflection-absorption infrared spectra (RAIRS) of $\mathrm{CH}_{3} \mathrm{I}$ on $\mathrm{Pd}(1111)$ are displayed in Fig. 6. The spectra of $\mathrm{CD}_{3} \mathrm{I}$ were also collected (not shown) and exhibit features identical to those found on $\operatorname{Pt}\left(\begin{array}{lll}1 & 1 & 1\end{array}\right)$ [11]. The bottom spectra in Fig. 6 are for increasing methyl iodide exposures at a sample temperature of $80 \mathrm{~K}$ (where the exposures are marked adjacent to the corresponding spectrum). These display features at 884 , $1215,1225,1243,1428$ and $2932 \mathrm{~cm}^{-1}$. The peaks at 1215 and $1411 \mathrm{~cm}^{-1}$ grow only slowly as a function of increasing methyl iodide exposure while those at 884,1243 and $1428 \mathrm{~cm}^{-1}$ grow more rapidly without saturation. As the surface is heated to $120 \mathrm{~K}$, the 1243 - and $1428-\mathrm{cm}^{-1}$ peaks essentially

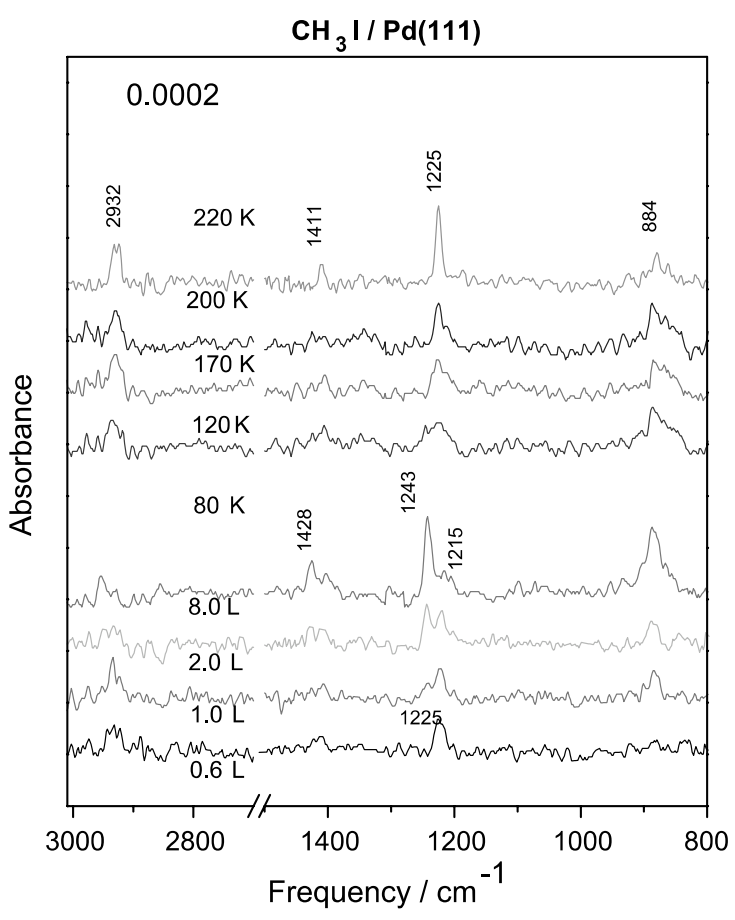

Fig. 6. Reflection infrared absorption spectrum of methyl iodide $\left(\mathrm{CH}_{3} \mathrm{I}\right)$ adsorbed onto $\mathrm{Pd}\left(\begin{array}{lll}1 & 1 & 1\end{array}\right)$ at $80 \mathrm{~K}$ as a function of methyl iodide exposure where these are marked adjacent to the corresponding spectrum. Also shown are spectra collected after heating to various temperatures where the annealing temperature are marked adjacent to the corresponding spectra.

disappear while that at $884 \mathrm{~cm}^{-1}$ is substantially diminished in intensity. A broad feature is observed centered at $1225 \mathrm{~cm}^{-1}$, which has been assigned to a compressed methyl iodide layer [11]. A temperature of $120 \mathrm{~K}$ corresponds to the multilayer desorption temperature in TPD (Fig. 1) and also that at which $\mathrm{C}-\mathrm{I}$ bond cleavage takes place (between 110 and $150 \mathrm{~K}[12,14]$ ). Thus, these features may either be assigned to compressed methyl iodide species on the $\operatorname{Pd}\left(\begin{array}{lll}1 & 1 & 1\end{array}\right)$ surface [11] or to adsorbed methyl species and, most likely, to a combination of both. Note that molecular methyl iodide desorbs at $\sim 229 \mathrm{~K}$ (Fig. 1), so that the shoulder on the $1225-\mathrm{cm}^{-1}$ feature after annealing to $200 \mathrm{~K}$ is likely due to remaining molecular species. Assignments are summarized in Table 1. The spectrum formed by heating to $170 \mathrm{~K}$ (when all of the multilayer has desorbed (Fig. 1), and $\mathrm{C}-\mathrm{I}$ bond cleavage is complete $[12,14])$ shows the 
Table 1

Assignments of the features in the RAIRS spectrum of $8 \mathrm{~L}$ of methyl iodide $\left(\mathrm{C}_{3 \mathrm{v}}\right.$ symmetry) adsorbed on $\mathrm{Pd}\left(\begin{array}{lll}1 & 1 & 1\end{array}\right)$ at $80 \mathrm{~K}$ (Fig. 6)

\begin{tabular}{llll}
\hline Symmetry & Mode & $\begin{array}{l}\text { Gas-phase } \\
\mathrm{CH}_{3} \mathrm{I} / \mathrm{cm}^{-1} \\
{[24]}\end{array}$ & $\begin{array}{l}\mathrm{CH}_{3} \mathrm{I} / \\
\mathrm{Pd}(111) / \\
\mathrm{cm}^{-1}\end{array}$ \\
\hline $\mathrm{e}(x, y)$ & $v_{\mathrm{a}}\left(\mathrm{CH}_{3}\right)$ & 3060 & - \\
$\mathrm{a}_{1}(z)$ & $v_{\mathrm{s}}\left(\mathrm{CH}_{3}\right)$ & 2933 & 2932 \\
$\mathrm{e}(x, y)$ & $\delta_{\mathrm{a}}\left(\mathrm{CH}_{3}\right)$ & 1436 & 1428 \\
$\mathrm{a}_{1}(z)$ & $\delta_{\mathrm{s}}\left(\mathrm{CH}_{3}\right)$ & 1252 & 1215 \\
$\mathrm{e}(x, y)$ & $\rho\left(\mathrm{CH}_{3}\right)$ & 882 & 884 \\
\hline
\end{tabular}

$\delta$-deformation, $\rho$-rock, $v$-stretch.

appearance of an additional sharper feature at $1225 \mathrm{~cm}^{-1}$. As the surface is heated, the broad $1215-\mathrm{cm}^{-1}$ mode loses some of its intensity and the $1225-\mathrm{cm}^{-1}$ peak becomes sharper. After heating to $220 \mathrm{~K}$, the spectrum consists of two sharp features at 1225 and $2932 \mathrm{~cm}^{-1}$. This temperature corresponds to the completion of the low-temperature methane desorption state (Fig. 1), and the desorption of the residual molecular $\mathrm{CH}_{3} \mathrm{I}$. This suggests that a portion of the methyl species present on the surface at $120 \mathrm{~K}$ hydrogenates to methane yielding the 191-K methane desorption state and the species present at $220 \mathrm{~K}$ yields the high-temperature (304-K) state.

The reflection-absorption infrared spectra of $\mathrm{CH}_{2} \mathrm{I}_{2}$ adsorbed on $\mathrm{Pd}\left(\begin{array}{lll}1 & 1 & 1\end{array}\right)$ are displayed in Fig. 7 both as a function of exposure (Fig. 7, bottom three spectra) and after heating the surface to various temperatures (Fig. 7, top two spectra). The exposures and annealing temperatures are displayed adjacent to the corresponding spectra. The spectra following adsorption at $80 \mathrm{~K}$ exhibit major features at 1109 and $3043 \mathrm{~cm}^{-1}$ which grow with increasing exposure, as well as a feature at 1079 $\mathrm{cm}^{-1}$ which is present at low exposures, but which does not grow as the exposure increases. The peaks that grow with exposure are due to molecular methylene iodide and can be assigned by comparison with the gas-phase spectrum and the assignments are displayed in Table 2. Two different arrangements of condensed layers have been identified when $\mathrm{CH}_{2} \mathrm{I}_{2}$ was deposited onto $\mathrm{Al}\left(\begin{array}{lll}1 & 1 & 1\end{array}\right)$ [25] with features at 1109 and $1095 \mathrm{~cm}^{-1}$ and with a transition temperature between the two of $\sim 130$ $K$. Evidently modes of $a_{1}, b_{1}$ and $b_{2}$ symmetry are
RAIRS of $\mathrm{CH}_{2} \mathrm{I}_{2} / \mathrm{Pd}(111)$

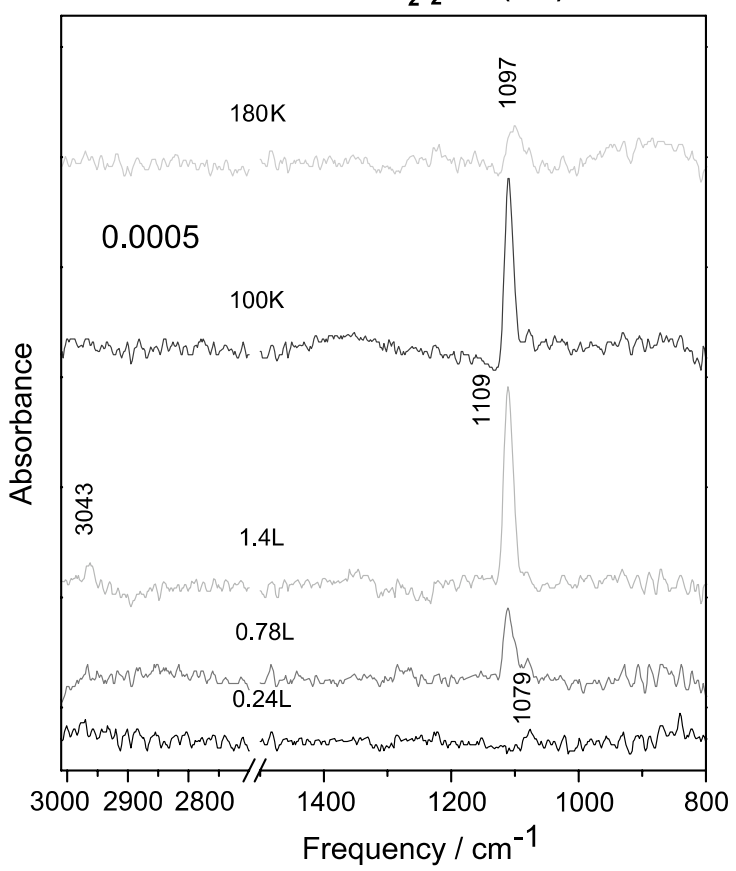

Fig. 7. Reflection infrared absorption spectrum of methylene iodide $\left(\mathrm{CH}_{2} \mathrm{I}_{2}\right)$ adsorbed onto $\mathrm{Pd}\left(\begin{array}{lll}1 & 1 & 1\end{array}\right)$ at $80 \mathrm{~K}$ as a function of methyl iodide exposure where these are marked adjacent to the corresponding spectrum. Also shown are spectra collected after heating to various temperatures where the annealing temperature are marked adjacent to the corresponding spectra.

Table 2

Assignments of the features in the RAIRS spectrum of methylene iodide $\left(\mathrm{C}_{2 \mathrm{v}}\right.$ symmetry) adsorbed on $\mathrm{Pd}\left(\begin{array}{lll}1 & 1 & 1\end{array}\right)$ at $80 \mathrm{~K}$ (Fig. 7)

\begin{tabular}{llll}
\hline Symmetry & Mode & $\begin{array}{l}\text { Gas-phase fre- } \\
\text { quency/cm }\end{array}$ & $\begin{array}{l}\text { Frequency/ } \\
\mathrm{cm}^{-1}\end{array}$ \\
\hline $\mathrm{b}_{2}(x)$ & $v_{\mathrm{a}}\left(\mathrm{CH}_{2}\right)$ & 3047 & 3043 \\
$\mathrm{a}_{1}(z)$ & $v_{\mathrm{s}}\left(\mathrm{CH}_{2}\right)$ & 2968 & 2960 \\
$\mathrm{a}_{1}(z)$ & $\delta\left(\mathrm{CH}_{2}\right)$ & 1349 & - \\
$\mathrm{b}_{1}(y)$ & $\omega\left(\mathrm{CH}_{2}\right)$ & 1103 & 1109 \\
$\mathrm{a}_{2}(-)$ & $\gamma\left(\mathrm{CH}_{2}\right)$ & 1028 & - \\
$\mathrm{b}_{2}(x)$ & $\rho\left(\mathrm{CH}_{2}\right)$ & 714 & - \\
\hline
\end{tabular}

$\delta$-deformation, $\rho$-rock, $v$-stretch, $\gamma$-twist, $\omega$-wag.

all detected on $\operatorname{Pd}\left(\begin{array}{lll}1 & 1 & 1\end{array}\right)$ implying that the molecular overlayer adopts no preferential high-symmetry geometry on this surface. As the sample is heated to $100 \mathrm{~K}$, the $\mathrm{C}-\mathrm{H}$ stretching mode disappears leaving an intense feature at $1109 \mathrm{~cm}^{-1}$ (due 
to the $\omega\left(\mathrm{CH}_{2}\right)$ mode). As the sample is heated to $\sim 180 \mathrm{~K}$, the $1109-\mathrm{cm}^{-1}$ feature attenuates substantially in intensity, the peak at $1079 \mathrm{~cm}^{-1}$ persists, and a feature grows at $\sim 1097 \mathrm{~cm}^{-1}$. Features detected at $1061 \mathrm{~cm}^{-1}$ on $\mathrm{Mo}(100)$ [26] and 1097 $\mathrm{cm}^{-1}$ on $\operatorname{Ag}\left(\begin{array}{lll}1 & 1 & 1\end{array}\right)$ [27] have been assigned to the presence of $\mathrm{CH}_{2(\mathrm{ads})}$ and since a feature is present at close to this value at low coverages $\left(1079 \mathrm{~cm}^{-1}\right.$, Fig. 7), it is likely that this feature is due to a similar species. These observations are in accord with those found for methylene iodide on $\operatorname{Pd}\left(\begin{array}{lll}1 & 0 & 0\end{array}\right)$ [9] where some C-I bond cleavage was detected even at $90 \mathrm{~K}$ and where total dissociation occurred at between 160 and $230 \mathrm{~K}$. If the principle $\mathrm{C}_{2}$ axis of the methylene species were oriented perpendicular to the surface, only modes of $\mathrm{a}_{1}$ symmetry should be allowed. However, the $\omega\left(\mathrm{CH}_{2}\right)$ mode has $b_{1}$ symmetry (Table 2) which may indicate that this species is somewhat tilted with respect to the $\operatorname{Pd}\left(\begin{array}{llll}1 & 1 & 1\end{array}\right)$ surface.

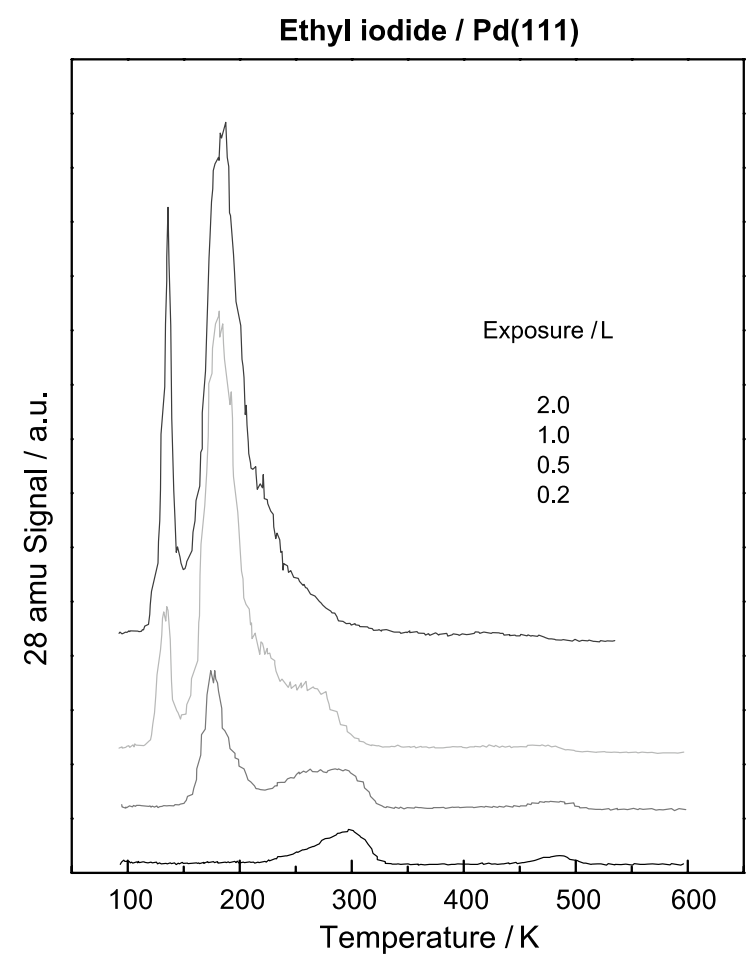

Fig. 8. TPD spectra of $\mathrm{C}_{2} \mathrm{H}_{5} \mathrm{I}$ adsorbed on $\mathrm{Pd}\left(\begin{array}{lll}1 & 1 & 1\end{array}\right)$ at $80 \mathrm{~K}$ collected using a heating rate of $7 \mathrm{~K} / \mathrm{s}$ as a function of $\mathrm{C}_{2} \mathrm{H}_{5} \mathrm{I}$ exposure monitoring 28 amu (ethylene). $\mathrm{C}_{2} \mathrm{H}_{5} \mathrm{I}$ exposures are marked adjacent to the corresponding spectra.
In order to compare the rates of $\alpha$ - and $\beta$ hydrogen elimination on $\operatorname{Pd}(111)$, a series of 28amu TPD spectra were collected for ethyl iodide adsorbed on $\operatorname{Pd}\left(\begin{array}{llll}1 & 1 & 1\end{array}\right)$ and the results are displayed in Fig. 8. These spectra were collected using exactly identical conditions to those for methyl iodide allowing direct comparison between the results. At low ethyl iodide exposures $(0.2 \mathrm{~L}$, Fig. 8 ), a small 28-amu feature is detected at $300 \mathrm{~K}$. An additional feature appears at $\sim 175 \mathrm{~K}$ for ethyl iodide exposures greater than $0.5 \mathrm{~L}$ and sharp feature is found at $\sim 130 \mathrm{~K}$ at higher exposures assigned to the fragmentation of desorbing ethyl iodide multilayers.

\section{Discussion}

Multilayer $\mathrm{CD}_{3} \mathrm{I}$ desorbs from clean $\mathrm{Pd}\left(\begin{array}{lll}1 & 1 & 1\end{array}\right)$ at $127 \mathrm{~K}$ with the monolayer desorbing at $229 \mathrm{~K}$ (Figs. 1 and 2). The infrared spectrum of $8.0 \mathrm{~L}$ of $\mathrm{CH}_{3} \mathrm{I}$ at $80 \mathrm{~K}$ on $\mathrm{Pd}\left(\begin{array}{lll}1 & 1 & 1\end{array}\right)$ (Fig. 6) exhibits a series of features at 884, 1243 and $1428 \mathrm{~cm}^{-1}$, which disappear as the surface is heated to $120 \mathrm{~K}$. This temperature corresponds to both the multilayer desorption temperature (Fig. 1) as well as that at which the C-I bond starts to cleave $[12,14]$. This therefore indicates that these features are due to molecular methyl iodide on the surface. These peaks can be straightforwardly assigned by comparison with gas-phase methyl iodide [24] and the assignments are displayed in Table 1. Note, however, that the relative intensities of the multilayer 1243- and $884-\mathrm{cm}^{-1}$ features vary with exposure. If the $\mathrm{C}-\mathrm{I}$ bond of multilayer methyl iodide were oriented perpendicularly to the surface, according to the RAIRS surface selection rules, only modes of $\mathrm{a}_{1}$ symmetry should be allowed if the molecule maintains its $C_{3 v}$ symmetry on the surface. This would result in only the $1243-$ and $2953-\mathrm{cm}^{-1}$ modes being detected. Conversely, if the $\mathrm{C}-\mathrm{I}$ axis were parallel to the surface, only e modes would be detected. Clearly, the detection of modes of both $\mathrm{a}_{1}$ and e symmetry for the multilayer indicates that the $\mathrm{C}-\mathrm{I}$ axis is oriented at some intermediate angle to the surface. In addition, it is clear that the intensity ratio of the $1243-\left(\mathrm{a}_{1}\right)$ and $884-\mathrm{cm}^{-1}$ (e) mode varies with exposure. The ratio 
$\mathrm{I}(1243) / \mathrm{I}(884)$ is tabulated as a function of methyl iodide exposure in Table 3. Since the $1243-\mathrm{cm}^{-1}$ mode is of $\mathrm{a}_{1}$ symmetry and that at $883 \mathrm{~cm}^{-1}$ of e symmetry, according to the above argument, this ratio should be infinity if the $\mathrm{C}-\mathrm{I}$ bond is perpendicular to the surface, and zero if it is parallel. Clearly, the variation in this ratio as the exposure increases indicates that the methyl iodide orientation, while tilted throughout the whole measured exposure range, changes as the coverage increases.

Heating the surface to $120 \mathrm{~K}$ gives rise to broad features at 2932 and $1215 \mathrm{~cm}^{-1}$ with sharper peaks at 1411 and $884 \mathrm{~cm}^{-1}$. As noted above, $120 \mathrm{~K}$ is close to both the multilayer desorption temperature and that at which substantial C-I bond cleavage is underway $[12,14]$ and these features are assigned to the presence of a mixture of adsorbed methyl iodide [11] and methyl species. Again, these peaks can be assigned by comparison to gas-phase methyl iodide and the assignments are shown in Table 4 . Since peaks of both $a_{1}$ and e symmetry are evident in the spectrum, this indicates that, after annealing to $120 \mathrm{~K}$, the symmetry axis of the adsorbed species is tilted with respect to the surface. As the sample is heated to 200 and $220 \mathrm{~K}$, the

Table 3

Ratio of the intensity of the $1243-\mathrm{cm}^{-1}$ mode to that of the 883$\mathrm{cm}^{-1}$ peak as a function of methyl iodide exposure

\begin{tabular}{ll}
\hline $\mathrm{CH}_{3} \mathrm{I}$ exposure/L & $\mathrm{I}(1243) / \mathrm{I}(884)$ \\
\hline 1.0 & 0.6 \\
2.0 & 1.8 \\
8.0 & 1.4 \\
\hline
\end{tabular}

Table 4

Assignments of the features in the RAIRS spectrum of methyl species $\left(\mathrm{C}_{3 \mathrm{v}}\right.$ symmetry) formed by adsorbing methyl iodide on $\mathrm{Pd}\left(\begin{array}{lll}1 & 1 & 1)\end{array}\right)$ at $80 \mathrm{~K}$ and heating to 120 and $220 \mathrm{~K}$ (Fig. 6)

\begin{tabular}{lllll}
\hline Symmetry & Mode & $\begin{array}{l}\text { Gas-phase } \\
\mathrm{CH}_{3} \mathrm{I} / \\
\mathrm{cm}^{-1}[24]\end{array}$ & $\begin{array}{l}\mathrm{CH}_{3} \mathrm{I} / \\
\mathrm{Pd}(111) / \\
\mathrm{cm}^{-1}(120 \\
\mathrm{K})\end{array}$ & $\begin{array}{l}\mathrm{CH}_{3} \mathrm{I} / \\
\mathrm{Pd}(11) / \\
\mathrm{cm}^{-1}(220 \\
\mathrm{K})\end{array}$ \\
\hline $\mathrm{e}(x, y)$ & $v_{\mathrm{a}}\left(\mathrm{CH}_{3}\right)$ & 3060 & - & - \\
$\mathrm{a}_{1}(z)$ & $v_{\mathrm{s}}\left(\mathrm{CH}_{3}\right)$ & 2933 & 2932 & 2932 \\
$\mathrm{e}(x, y)$ & $\delta_{\mathrm{a}}\left(\mathrm{CH}_{3}\right)$ & 1436 & - & - \\
$\mathrm{a}_{1}(z)$ & $\delta_{\mathrm{s}}\left(\mathrm{CH}_{3}\right)$ & 1252 & 1215 & 1225 \\
$\mathrm{e}(x, y)$ & $\rho\left(\mathrm{CH}_{3}\right)$ & 882 & 884 & - \\
\hline
\end{tabular}

$\delta$-deformation, $\rho$-rock, $v$-stretch. $884-\mathrm{cm}^{-1}$ peak disappears and the spectrum consists of features at 1225 and $2932 \mathrm{~cm}^{-1}$. These can again be assigned by comparison with the gasphase spectrum and the assignments are also displayed in Table 4. Now only features of $a_{1}$ symmetry are seen indicating that the symmetry axis of the methyl group is oriented perpendicularly to the surface. Comparison with the methane desorption spectra for high methyl iodide coverages (Figs. 1 and 2) suggests that the low-temperature (191-K) state is associated with the broad feature centered at $\sim 1215 \mathrm{~cm}^{-1}$, while the hightemperature methane formation state is due to the hydrogenation of a methyl group with the C-Pd bond perpendicular to the surface. Heating to 170 $\mathrm{K}$ forms perpendicular methyl species and causes a significant decrease in intensity of the $1215-\mathrm{cm}^{-1}$ feature (Fig. 6). C-I bond cleavage is complete at this temperature $[12,14]$ so that the broad shoulder at $1215 \mathrm{~cm}^{-1}$ in this spectrum is entirely due to methyl species and the relatively large $884-\mathrm{cm}^{-1}$ intensity implies that this is tilted on the surface indicating that the low-temperature (191-K) formation of methane is due to the hydrogenation of tilted methyl species, while the high-temperature state arises from the hydrogenation of perpendicular ones.

It is also clear, however, from the TPD data of Figs. 2 and 3 that the coverage has a profound effect on the hydrogenation kinetics. Comparing these spectra reveals that hydrogen desorbs at $\sim 359 \mathrm{~K}$ while, at low coverages, methane is evolved in a single peak at $\sim 219 \mathrm{~K}$. As the exposure increases to $2 \mathrm{~L}$, the $219 \mathrm{~K}$ (methane) peak grows, while the $359 \mathrm{~K}$ (deuterium) feature decreases slightly in intensity. Since the $219-\mathrm{K}$ desorption state appears to shift smoothly toward the 191-K state as the methyl iodide coverage increases, this implies that the $219-\mathrm{K}$ state is similarly due to the hydrogenation of a tilted methyl species. The decrease in the amount of hydrogen formed as the coverage increases is then ascribed to the lack of space available on the surface for dehydrogenation. This suggestion is supported by the further decrease in the amount of hydrogen desorption that occurs as the exposure is increased to saturation $(6 \mathrm{~L})$. Thus, the relative rates of hydrogenation and dehydrogenation appear to 
depend on the neighboring sites available to accept the hydrogen and is limited by the crowded surface. As the exposure increases to $3 \mathrm{~L}$, another state appears at $\sim 270 \mathrm{~K}$, which shifts to $304 \mathrm{~K}$ as the coverage approaches saturation. The exposure of $3 \mathrm{~L}$ corresponds to $\sim 50 \%$ of the saturation coverage and the high-temperature methane state was suggested above to be due to the hydrogenation of a perpendicular methyl species. In this case, presumably there is insufficient hydrogen on the surface to completely consume the more easily hydrogenated, tilted methyl state so that it converts into a more stable, but less easily hydrogenated perpendicular state. This conjecture is confirmed by the desorption spectrum in Fig. 4 which shows the effect of pre-dosing the surface with deuterium $(10 \mathrm{~L})$ and then saturating with methyl iodide. Now there is sufficient hydrogen on the surface to completely react with the tilted methyl species on the surface which desorbs in a state at $\sim 209 \mathrm{~K}$.

The variation in the temperature of the methane desorption state when the $\mathrm{CD}_{3} \mathrm{I}$ exposure is increased (Fig. 5) is interesting. The intensity of this feature increases with increasing $\mathrm{CD}_{3} \mathrm{I}$ exposure as expected. However, surprisingly the peak temperature increases with increasing $\mathrm{CD}_{3} \mathrm{I}$ exposure, while it would be anticipated that increasing the methyl iodide (and correspondingly the methyl) coverage would result in a decrease in desorption temperature. The observation that the desorption temperature increases with increasing exposure suggests that there are strong interactions between the adsorbed species that affects the activation energy to methane formation.

It has been suggested that methyl species adsorbed on $\operatorname{Pd}\left(\begin{array}{lll}1 & 1 & 1\end{array}\right)$, when formed from methanol, can be stable up to $\sim 400 \mathrm{~K}$ [28]. The detection of methane desorption states at $\sim 304 \mathrm{~K}$ (Fig. 1) confirms that the methyl species with the $\mathrm{C}_{3}$ symmetry axis oriented perpendicular to the surface is stable to at least this temperature. However, in addition, a small 4-amu feature is detected centered at $\sim 360 \mathrm{~K}$ with a tail extending to a little above $400 \mathrm{~K}$. The data of Fig. 4, for example, shows that atomic deuterium on the surface desorbs at $\sim 300 \mathrm{~K}$, indicating that the high-temperature 4-amu state in Fig. 1 is due to the thermal decomposition of a surface $\mathrm{CH}_{x}$ species. It is not clear however, whether this is some remaining perpendicular methyl species or a methylene species deriving from this. To explore this possibility, methylene species were grafted onto the surface by reacting it with $\mathrm{CH}_{2} \mathrm{I}_{2}$. The resulting RAIRS spectra are displayed in Fig. 7. Comparing the spectra obtained for methylene species (Fig. 7) with the RAIRS data obtained by warming a $\mathrm{CH}_{3}$ covered surface (Fig. 6), it is found that the formation of $\mathrm{CH}_{2}$ species at high temperatures is not a major reaction pathway.

Assuming that the methane formation rate from methyl iodide on metal surfaces is limited by the rate of $\alpha$-hydrogen elimination to yield the available hydrogen allows the rate on $\operatorname{Pd}\left(\begin{array}{lll}1 & 1 & 1\end{array}\right)$ to be compared with those for other transition metals. Methane is formed at $219 \mathrm{~K}$ from methyl

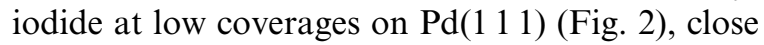

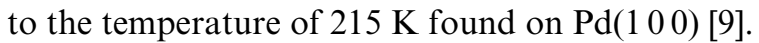
Note, however, that these values must be used with caution since methane desorbs at only slightly lower temperatures ( $\sim 190 \mathrm{~K}$, Fig. 5) from low cov erages of methyl iodide from hydrogen-covered $\operatorname{Pd}\left(\begin{array}{lll}1 & 1 & 1\end{array}\right)$. However, the differences are sufficiently large that the methane formation temperature of $219 \mathrm{~K}$ for low coverages on methyl iodide on $\operatorname{Pd}\left(\begin{array}{lll}1 & 1 & 1\end{array}\right)$ likely reflects the rate of hydrogen formation. The corresponding temperatures are 170

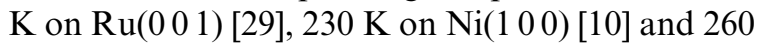
$\mathrm{K}$ on $\mathrm{Pt}\left(\begin{array}{lll}1 & 1 & 1\end{array}\right)$ [11] showing the expected trend of decreasing temperature, indicating increased dehydrogenation activity, on moving toward the left of the d-transition series. A similar comparison for $\beta$-hydrogen elimination, measured from the ethylene desorption temperature from adsorbed ethyl species, which occurs at $175 \mathrm{~K}$ on $\operatorname{Pd}(111)$ (Fig. 8) shows that this is close to the value on $\operatorname{Pd}(100)$ of $180 \mathrm{~K}$ [30]. Comparing with the ethylene desorption temperatures from ethyl species on $\mathrm{Ni}\left(\begin{array}{lll}1 & 0 & 0\end{array}\right)$ (160 K [31]), Pt(1 1 1) (180 K [32]), Rh(1 11 ) (210 $\mathrm{K}$ [33]), $\mathrm{Fe}(100)$ (220 K [34]), Cu(1 00 ) (250 K [35]) and $\mathrm{Au}\left(\begin{array}{lll}1 & 1 & 1\end{array}\right)$ (265 K [36]), shows that the trend in reactivity in this case is that this increases in going upwards and to the left in the periodic table. Finally, the rate of $\beta$-hydride elimination, which has an activation energy of $\sim 10.5 \mathrm{kcal} / \mathrm{mol}$ on $\operatorname{Pd}(111)$, is more rapid than the rate of 
$\alpha$-hydride elimination which has an activation energy of $\sim 13.0 \mathrm{kcal} / \mathrm{mol}$.

\section{Conclusions}

Methyl iodide adsorbs on $\operatorname{Pd}\left(\begin{array}{lll}1 & 1\end{array}\right)$ at $80 \mathrm{~K}$ to form a molecular overlayer with subsequent adsorption into a multilayer where the methyl iodide orientation changes with coverage. The multilayer desorbs at $\sim 130 \mathrm{~K}$ and unreacted methyl iodide desorbs from the surface at $\sim 229$ K. Self-hydrogenation of methyl iodide is found in two states at high coverages where the low-temperature ( 191-K) state is proposed to be due to the hydrogenation of tilted methyl species while the high-temperature $(304-\mathrm{K})$ state is due to the hydrogenation of perpendicular methyl species. A single methane desorption state is found at lower coverages at $\sim 219 \mathrm{~K}$. Pre-dosing the surface with hydrogen completely suppresses the high-temperature methane desorption state yielding a peak between $\sim 189$ and $207 \mathrm{~K}$ depending on methyl iodide exposure. The rates of $\alpha$ - and $\beta$-hydride elimination on $\operatorname{Pd}\left(\begin{array}{lll}1 & 1 & 1\end{array}\right)$ are in accord with trends found previously on the noble metals where the rate of $\beta$-hydride elimination is faster than the rate of $\alpha$-hydride elimination.

\section{Acknowledgements}

We gratefully acknowledge support of this work by the US Department of Energy, Division of Chemical Sciences, Office of Basic Energy Sciences, under grant no. DE-FG02-92ER14289.

\section{References}

[1] F. Zaera, Chem. Rev. 95 (1995) 2651.

[2] B.E. Bent, Chem. Rev. 96 (1996) 1361.

[3] G. Wu, B. Bartlett, W.T. Tysoe, Langmuir 14 (1998) 1435.

[4] D. Stacchiola, S. Azad, L. Burkholder, W.T. Tysoe, J. Phys. Chem. B 105 (2001) 11233.
[5] X.-L. Zhou, F. Solymosi, P.M. Blass, K.C. Cannon, J.M. White, Surf. Sci. 219 (1989) 294.

[6] M.X. Zhang, S.K. To, A. Paul, L. Avila, B.E. Bent, K. Nishikida, Surf. Sci. 325 (1995) 102.

[7] X.-L. Zhou, J.M. White, J. Phys. Chem. 95 (1991) 5575.

[8] G. Wu, D. Stacchiola, M. Kaltchev, W.T. Tysoe, J. Am. Chem. Soc. 122 (2000) 8232.

[9] F. Solymosi, K. Revész, J. Am. Chem. Soc. 113 (1991) 9145.

[10] S. Tjandra, F. Zaera, Langmuir 8 (1992) 2090.

[11] F. Zaera, H.J. Hoffmann, J. Phys. Chem. 95 (1991) 6297.

[12] J.J. Chen, N. Winograd, Surf. Sci. 314 (1994) 188.

[13] D. Stacchiola, L. Burkholder, W.T. Tysoe, Surf. Sci. 511 (2002) 215.

[14] M.T. Buelow, B. Immaraporn, A.J. Gellman, J. Catal. 203 (2001) 41.

[15] C.W.J. Bol, C.M. Friend, J. Am. Chem. Soc. 117 (1995) 11572 .

[16] I. Kovács, F. Solymosi, J. Mol. Catal. A 141 (1999) 31.

[17] F. Solymosi, I. Kovács, K. Revész, Surf. Sci. 356 (1996) 121.

[18] A. Kis, J. Kis, F. Solymosi, Surf. Sci. 459 (2000) 149.

[19] H. Wu, H. Hsu, C. Chiang, J. Am. Chem. Soc. 121 (1999) 4433.

[20] F. Solymosi, I. Kovács, Surf. Sci. 296 (1993) 171.

[21] S. Monin, P.H. McBreen, Surf. Sci. 264 (1992) 341.

[22] G. Wu, M. Kaltchev, W.T. Tysoe, Surf. Rev. Lett. 6 (1999) 13.

[23] M. Kaltchev, W.T. Tysoe, J. Catal. 196 (2000) 40.

[24] T. Shimanouchi, Molecular vibrational frequencies, in: W.G. Mallard, P.J. Linstrom (Eds.), NIST Chemistry WebBook, NIST Standard Reference Database Number 69, November 1998, National Institute of Standards and Technology, Gaithersburg MD, 20899.

[25] J.N. Kendo, T. Higashi, H. Yamamoto, M. Hara, K. Domem, T. Onishi, Surf. Sci. 349 (1996) 294.

[26] G. Wu, M. Kaltchev, W.T. Tysoe, Surf. Rev. Lett. 6 (1999) 13.

[27] G. Wu, D. Stacchiola, M. Collins, W.T. Tysoe, Surf. Rev. Lett. 3/4 (2001) 303.

[28] R.J. Lewis, Z.C. Jiang, N. Winograd, J. Am. Chem. Soc. 110 (1988) 4431.

[29] Y. Zhou, M.A. Henderson, W.M. Feng, J.M. White, Surf. Sci. 224 (1989) 386.

[30] T. Kovács, F. Solymosi, J. Phys. Chem. 97 (1993) 11056.

[31] S. Tjandra, F. Zaera, J. Vac. Sci. Technol. A 10 (1992) 404.

[32] F. Zaera, J. Phys. Chem. 94 (1990) 8350.

[33] F. Solymosi, L. Bugyi, A. Oszkó, Langmuir 12 (1996) 4145.

[34] M.L. Burke, R.J. Madix, J. Am. Chem. Soc. 113 (1991) 2675.

[35] C.J. Jenks, M. Xi, M.X. Yang, B.E. Bent, J. Phys. Chem. 98 (1994) 2152.

[36] A. Paul, M.X. Yang, B.E. Bent, Surf. Sci. 297 (1993) 327. 